"Mircea cel Batran" Naval Academy Scientific Bulletin, Volume XIX - 2016 - Issue 2 The journal is indexed in: PROQUEST I DOAJ / Crossref / EBSCOhost / INDEX COPERNICUS / DRJI / OAJI I JOURNAL INDEX / I2OR / SCIENCE LIBRARY INDEX / Google Scholar / Academic Keys/ ROAD Open Access I Academic Resources / Scientific Indexing Services / SCIPIO I JIFACTOR

\title{
TACTICAL DATA LINK - FROM LINK 1 TO LINK 22
}

\author{
Anca STOICA ${ }^{1}$ \\ Diana MILITARU ${ }^{2}$ \\ Dan MOLDOVEANU ${ }^{3}$ \\ Alina POPA ${ }^{4}$
}

${ }^{1}$ Scientific research assistant, Lt. Eng.Military Equipment and Technologies Research Agency
16 Aeroportului street, Clinceni, Ilfov, astoica@acttm.ro
${ }^{2}$ Scientific researcher, PhD Eng. Military Equipment and Technologies Research Agency
${ }^{3}$ Scientific research Assistant, SIt. Eng. Military Equipment and Technologies Research Agency
${ }^{4}$ Scientific research assistant, Eng. Military Equipment and Technologies Research Agency

Abstract: Tactical data links (TDL) are elements of C4ISR system, which provide a continuous data exchange in (nearly) real time about space, ground, air, surface and subsurface platforms including allied, neutral and foe units data. The main scope of TDL is to provide the operation monitoring capability (for commander) and to send particular commands and data (for subordinates), being one of the basic components of network centric warfare concept implementation. A TDL uses data link standards in order to provide communication via radio waves or cable to transmit, relay and receive tactical encrypted data. This paper aims to outline a comparison between the main TDL standards and their capabilities.

Key words: tactical data link, Link 1, Link 11, Link 16, Link 22

\section{Introduction}

There is an unprecedented rise in the data and information volume needed for planning, decisionmaking and commanding military actions. The information about targets, troops' movement and their condition, supply levels and availability of resources - for all belligerent parties (our own, the allied and the opponent's) - must be supplied to the joint commandment and its forces, considering that it is obtained from geographically dispersed equipments. Thus, it is necessary that information to be delivered to commanders in time, at the right location and in the required form, in order for them to make decisions (in command and control processes) in near-real time, during military action deployment by the joint forces.
The "data link" term refers to all technologies, applications and messages package used in the communication system. The military "tactical data link" term represents the data links used as support in military actions. Known data links were designed according to specific standards such as Link 1, Link 4, Link 11, Link 14, Link 16 or Link 22. Each of them has been developed for specific military communication requirements. Some of them are obsolete, but still in use (e.g. Link 1). On the other hand, Link 16 and Link 22 are the newest and most advanced tactical data link networks. With respect to the above discussion, we will present a short description of these standards.

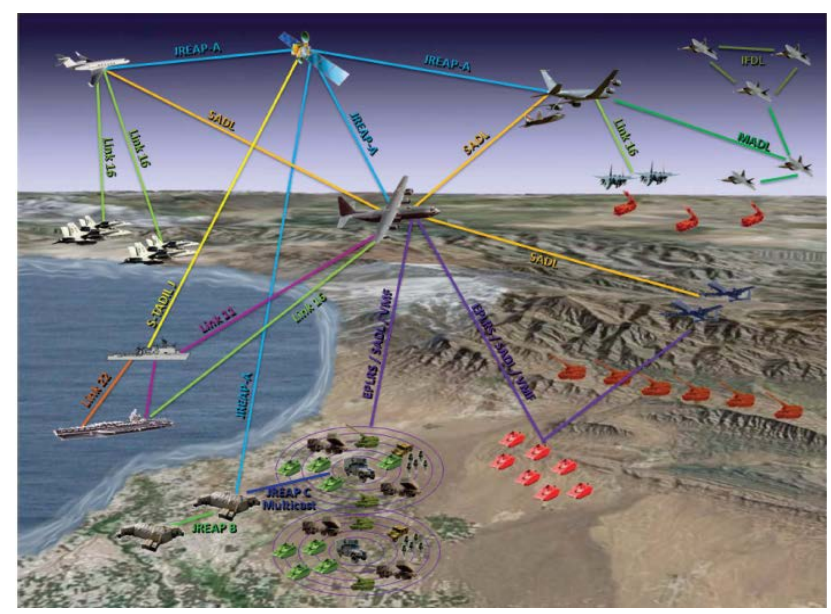

Figure.1. Example of Tactical Data Link (TDL) Usage [1] Table 1. TDL systems which NATO uses 
"Mircea cel Batran" Naval Academy Scientific Bulletin, Volume XIX - 2016 - Issue 2

The journal is indexed in: PROQUEST / DOAJ / Crossref / EBSCOhost / INDEX COPERNICUS / DRJI / OAJI I JOURNAL INDEX I I2OR / SCIENCE LIBRARY INDEX / Google Scholar / Academic Keys/ ROAD Open Access I Academic Resources / Scientific Indexing Services / SCIPIO I JIFACTOR

\begin{tabular}{|c|c|l|l|}
\hline Link type & User community & \multicolumn{1}{|c|}{ Application } \\
\hline Link 1 & Aerial situation & $\begin{array}{l}\text { Interfaces with other networks (aerial control/ aerial defense), with } \\
\text { mobile systems and with the primary users group. }\end{array}$ \\
\hline Link 11 & $\begin{array}{l}\text { Marine control } \\
\text { Aerial control }\end{array}$ & $\begin{array}{l}\text { Provides tracking data exchange for image compilation and } \\
\text { transmission of orders in the C2 domain. }\end{array}$ \\
\hline Link 11B & Aerial defense & $\begin{array}{l}\text { Tactical information exchange between soil-based weapon systems, C2 } \\
\text { and surveillance systems and Link 11 network participating units. }\end{array}$ \\
\hline Link 16 & Joint & $\begin{array}{l}\text { High-throughput digital data link, without a nodal point (hub), which } \\
\text { includes EPM for engaging a multiple combat environment (terrestrial, } \\
\text { naval and aerial combat) }\end{array}$ \\
\hline Link 22 & Joint & $\begin{array}{l}\text { Designed for ensuring connectivity outside the direct line-of-sight } \\
\text { (BLOS), using DTDMA architecture. }\end{array}$ \\
\hline
\end{tabular}

\section{Tactical Data Link (TDL)}

The joint operations command must have TDL equipments in order to benefit from MIDS (Multifunctional Information Distribution Systems) networks input data, introduced by terrestrial forces, aerial forces, marine forces and military information organizations, according to the commandment's needs (as per its tasks and abilities), as well as to introduce specific data into these networks (figure 1). Table 1 presents general characteristics of TDLs.

TDL systems are potential solutions for implementing the concept of Joint Intelligence, Surveillance and Reconnaisance (JISR). The main JISR missions are: early warning, information support for operations planning, information about the enemy and the environment for situational assessment, data and information about targets, informational operations support, information for risk assessment and troops protection, The accomplishment of these missions depends on the TDLs specifications which will comply the following requirements: regularity, clarity, conciseness, standardization, verification, selective distribution and classification of information.

Depending on what messages are used to convey tactical data, the main TDL functions are:

a. TDL parameters information exchange;

b. Network management;

c. Precise Participant Location and Identification (PPLI)

d. Air surveillance;

e. Land surveillance;

f. Terrestrial surveillance;

g. Space surveillance;

h. Electronic surveillance;

i. Electronic warfare (EW);

j. Intelligence; k. Mission management;

I. Weapons coordination and management;

m. Air control;

n. Managementul informatic;

o. Free text exchange;

p. Voice communication exchange.

TDL usage depends on the military area of operation or drill area, as seen in Table 2.

Table 2. TDL functional areas

\begin{tabular}{|c|c|c|c|}
\hline Functional areas & $\begin{array}{c}\text { Link } \\
11\end{array}$ & $\begin{array}{c}\text { Link } \\
16\end{array}$ & $\begin{array}{c}\text { Link } \\
22\end{array}$ \\
\hline $\begin{array}{ll}\begin{array}{l}\text { Status } \\
\text { platform }\end{array} & \text { monitoring } \\
\end{array}$ & $x$ & $x$ & $x$ \\
\hline Air surveillance & $\mathrm{x}$ & $x$ & $\mathrm{x}$ \\
\hline Land surveillance & - & $x$ & $x$ \\
\hline Surface surveillance & $\mathrm{x}$ & $x$ & $x$ \\
\hline $\begin{array}{l}\text { Subsurface } \\
\text { surveillance }\end{array}$ & $x$ & $x$ & $x$ \\
\hline Space surveillance & - & $x$ & $x$ \\
\hline Electronic warfare & $x$ & $x$ & $x$ \\
\hline $\begin{array}{l}\text { Weapons } \\
\text { coordination }\end{array}$ & $x$ & $x$ & $\mathrm{x}$ \\
\hline Command & $\mathrm{x}$ & $x$ & $x$ \\
\hline Aircraft control & - & $x$ & $x$ \\
\hline $\begin{array}{l}\text { Network } \\
\text { management }\end{array}$ & - & $x$ & $x$ \\
\hline Imagistics & - & $x$ & - \\
\hline
\end{tabular}

Data exchange capability imposes that the transmission medium is available prior to initiating and starting any TDL system for landline communications and radio frequencies allocation. The main characteristics of the equipments connection scheme in tactical data links are presented in Table 3. 
"Mircea cel Batran" Naval Academy Scientific Bulletin, Volume XIX - 2016 - Issue 2 The journal is indexed in: PROQUEST / DOAJ / Crossref / EBSCOhost / INDEX COPERNICUS / DRJI / OAJI I JOURNAL INDEX I I2OR / SCIENCE LIBRARY INDEX / Google Scholar / Academic Keys/ ROAD Open Access I Academic Resources / Scientific Indexing Services / SCIPIO I JIFACTOR

Table 3. Characteristics of TDL networking scheme

\begin{tabular}{|l|c|c|c|c|}
\hline \multicolumn{1}{|c|}{ Characteristics } & Link 1 & Link 11 & Link 16 & Link 22 \\
\hline Frequency & Point-to-point land line & HF/ UHF & UHF/ Spread & HF/UHF Spread \\
\hline Speed (bit/sec) & 1,200 & 1,800 & $>57,600$ & - \\
\hline ECM resistance & - & - & $\mathrm{x}$ & $\mathrm{x}$ \\
\hline Crypto-secure & - & $\mathrm{x}$ & $\mathrm{x}$ & $\mathrm{x}$ \\
\hline Nodeless & - & - & $\mathrm{X}$ & $\mathrm{x}$ \\
\hline Extended LOS & - & - & $\mathrm{x}$ & $\mathrm{x}$ \\
\hline Antijam & - & - & $2.8 \div 115.2$ & 2.4 \\
\hline Data rate (kbps) & 1.2 & $1.3 \div 2.25$ & $\mathrm{~J}$ series & $\mathrm{J}$ series \\
\hline Standard message & S-series & M series & $>128$ & 40 \\
\hline Participants & & $4 \div 8$ & 2 & - \\
\hline Voice circuits & - & Radio Broadcast & TDMA & DTDMA \\
\hline Architecture & Duplex digital & &
\end{tabular}

\section{From Link 1 to Link 22}

In the Data Links evolution, there are two main generations. The first generation Data Links (Link1, Link4, Link11, Link11B, Link14) was developed on 8-bit computers, in 1950's and 1960's, with limited functionality and slow data rates (600 - 2400 bps). The second generation Data Links (Link16, Link22) was developed on 16bit computers, in the 1970's and 1980's, is multifunctional and works at faster data rates (2400bps-1Mbps).

\subsection{Link 1}

Link 1 is a point-to-point tactical link based on a fixed digital message set, which interconnects European NATO terrestrial counterair fixed locations in order to exchange data and information regarding the air situational awareness in the main network group.

\subsection{Link 11}

Link 11 is a secure half-duplex tactical data radio link used by NATO for digital information transmission among airborne, land-based, and ship-board tactical data systems. Link 11 works in HF or UHF band. Currently Link 11 is intended to be replaced by Link 22 . The standard that defines its specification is MIL-STD-6011.

\subsection{Link 16}

Link 16 is a high-capacity datalink, with frequency hopping features and jam resistance capabilities. Links 16 uses Joint Tactical Information Distribution System (JTIDS) terminals and Multifunctional Information Distribution System (MIDS). Link 16 has implemented the Time Division Multiple Access (TDMA) technique, that provides 128 time slots/second for the JU (JTIDS
Units) participants. The time slots are organized in several functional groups of network users.

Unlike Link1 and Link 11, Link 16 uses encryptied high-capacity datalink, with no single point of failure (NCS), and provides electronic protection measures for fully-operational communications in combat situations (air, terestrial, sea). In table no. 2 there are ilustrated main characteristics of the TDL developed by NATO over the past decades, including the oldest and the newest technologies available.

The main purpose of Link 16 is to provide the support for real-time tactical information exchange between joint units. Link 16 is allowing the tactical usage of the involved platforms (equiped with Link 16) and provides enhanced communication capabilities, which include::

- Nodelessness

- Jam resistance

- Increased data rate

- Increased volume of information exchange

- Reduced data terminal size, allowing installation in fighter and attack aircraft

- Digitized, jam-resistant, secure voice capability

- Precise Participant Location and Identification (PPLI)

Main applications where Link16 Tactical Data Link is used are:

- Surveillance

- Electronic War (EW)

- Mission Management (MM) / Weapons Coordination (WC)

- Air control

- Fighter-to-fighter net

- Secure voice channels

- Navigation 
"Mircea cel Batran" Naval Academy Scientific Bulletin, Volume XIX - 2016 - Issue 2

- Network management.

Link 16 is represented by several tactical data links which provide the information exchange using the Line of Sight radio medium. The available Link 16 terminals are:

- JTIDS - first generation terminals, including Class1 and Class2 terminals (software, hardware, RF equipment, and high-capacity, secure, anti-jam waveforms)

- MIDS-LVT - LVT1-LVT11 is the second generation class of Link 16 equipments

- JTRS şi MIDS JTRS - the future generation of Link 16 terminals.

\subsection{Link 22}

Same as Link 11, Link 22 is a secure digital radio link that works in the HF and UHF bands that provide the support for data exchange between air, ground, and navy of all the allied forces.

The one important thing about Link 22 is the fact that enables BLOS (Beyond Line of Sight) communication capabilities, so in the HF band Link 22 is able to provide communications up to 300 nautical miles distance. Unlike the HF communications which can provide both LOS and BLOS communications, the UHF band is designated only for LOS transmissions.

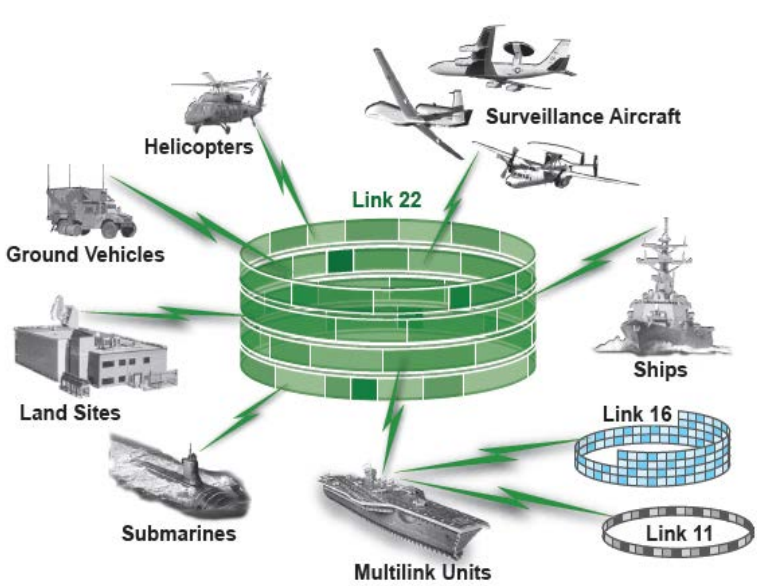

Figure 2. Link 22 Network Overview [1]

As we mentioned before, the Link 11 capabilities were limited, so the Link 22 initial program (NILE - NATO Improvement Link Eleven) objectives are:

- Link 11 upgrading and improvement;

- Allied Forces interoperability increasing;

- Link 16 complementary;

- C4ISR capabilities enhancement.

A visible improvement of Link 11 is the fact that Link 22 is able to be operational even in bad transmission conditions; it provides communication although at a lower data rate. In case of a specific unit failure, the whole network will not be affected because of the distributed protocols usage.

The design of Link 22 was similar to the standard ISO communications stack concept, which consists of several layers with individual and specific functions (Figure 3).

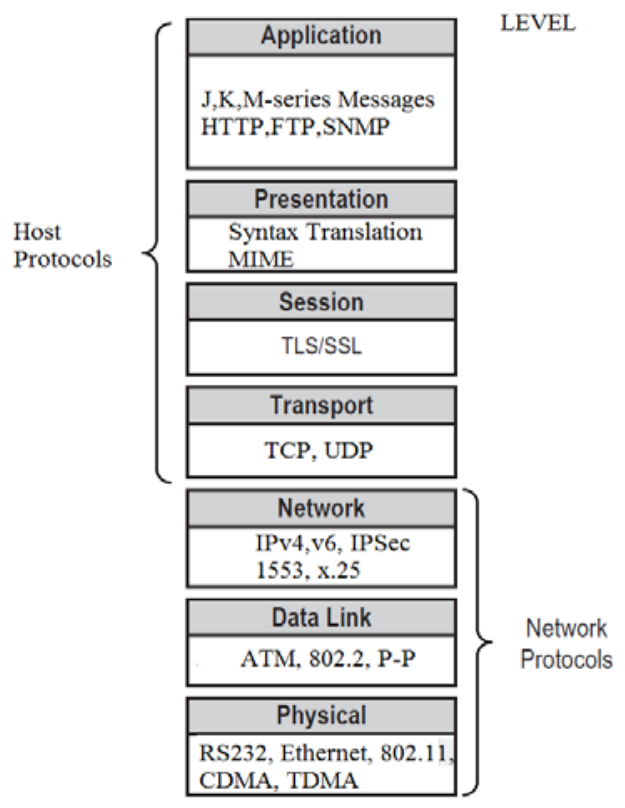

.Figure 3. The equivalent ISO OSI reference model [1] 
"Mircea cel Batran" Naval Academy Scientific Bulletin, Volume XIX - 2016 - Issue 2 The journal is indexed in: PROQUEST / DOAJ / Crossref / EBSCOhost / INDEX COPERNICUS / DRJI / OAJI I JOURNAL INDEX I I2OR / SCIENCE LIBRARY INDEX / Google Scholar / Academic Keys/ ROAD Open Access I Academic Resources / Scientific Indexing Services / SCIPIO / JIFACTOR

A synthetic comparison between Link11 and Link 22 is presented in Table 4

Table 4. A synthetic comparison between Link11 and Link 22

\begin{tabular}{|c|c|c|}
\hline \multirow{2}{*}{$\begin{array}{c}\text { Function/ } \\
\text { Specification }\end{array}$} & \multicolumn{2}{|c|}{ Parameters/Advantages/Limitations } \\
\hline & Link 11 & Link 22 \\
\hline Network Access & $\begin{array}{ll}\text { - } & \text { Increased net cycle times } \\
\text { - } \quad \text { Large access delay }\end{array}$ & $\begin{array}{ll}\text { - } & \text { TDMA access } \\
\text { - } & \text { Prioritization of messages } \\
& \text { feature }\end{array}$ \\
\hline Emergency calls & - $\quad$ No options & - $\quad$ Priority Injection feature \\
\hline Capacity & $\begin{array}{l}\text { - } \quad \text { Limited number of } \\
\text { participants (62) }\end{array}$ & - $\quad$ More units (125) \\
\hline $\begin{array}{l}\text { Area of } \\
\text { Operation } \\
\text { (Network } \\
\text { Coverage) }\end{array}$ & $\begin{array}{l}\text { - } \quad \text { Limited area } \\
\text { Dependence of the platforms } \\
\text { and their positions } \\
\text { - Units must be all connected } \\
\text { with the NCS }\end{array}$ & $\begin{array}{ll}\text { - } & \text { No limitation (it uses the WGS- } \\
& 84 \text { System); } \\
\text { - } & \text { Increased area of operation; } \\
\text { - } & \text { Flexibile network; } \\
\text { - } & \text { LOS and BLOS capabilities; } \\
\text { - } & \text { Routing\&relay protocols. }\end{array}$ \\
\hline $\begin{array}{l}\text { Communication } \\
\text { Security }\end{array}$ & $\begin{array}{ll}\text { - } & \text { Low encryption level } \\
\text { - } \quad \text { Weak security. }\end{array}$ & $\begin{array}{ll}\text { - } & \text { Strong encryption system. } \\
\text { - } & \text { Strong security. }\end{array}$ \\
\hline $\begin{array}{l}\text { Transmission } \\
\text { Security }\end{array}$ & $\begin{array}{ll}\text { - } & \text { Fixed HF or UHF } \\
\text { frequencies; } \\
\text { - } \quad \text { Jam vulnerabilities. }\end{array}$ & $\begin{array}{l}\text { - } \quad \text { Frequency hoping solutions } \\
\text { provide reliable } \\
\text { communications; } \\
\text { - Fixed frequency } \\
\text { communications are not so } \\
\text { affected as Link } 11 \text { because of } \\
\text { the multiple networks }\end{array}$ \\
\hline NCS failure & $\begin{array}{l}\text { - If NCS is down the entire } \\
\text { network will be affected }\end{array}$ & $\begin{array}{ll}\text { - } \quad & \text { No NCS required } \\
\text { - } \quad \text { No single point of failure }\end{array}$ \\
\hline Reliability & $\begin{array}{l}\text { - } \quad \text { Bad conditions could affect } \\
\text { the transmission } \\
\text { - } \quad \text { Limited waveforms } \\
\text { availability }\end{array}$ & $\begin{array}{l}\text { - } \quad \text { Special mechanism for bad } \\
\text { transmission conditions } \\
\text { - } \quad \text { More robust waveforms }\end{array}$ \\
\hline Bandwidth & $\begin{array}{l}\text { - } \quad \text { Limited Bandwidth } \\
\text { - } \quad \text { Transmission rates from } \\
\text { 1,090 bit/s to } 1,800 \mathrm{bit} / \mathrm{s}\end{array}$ & $\begin{array}{l}\text { - } \quad \text { Wider Bandwidth } \\
\text { - } \quad \text { Transmission rates from } 1,493 \\
\text { bit/s to } 12,666 \mathrm{bit} / \mathrm{s}\end{array}$ \\
\hline
\end{tabular}

\section{CONCLUSIONS}

Tactical Data Links provide near-real time combat information to U.S. and NATO allies about the integrated air picture with both friendly and hostile aircraft locations, and general situational awareness data, including defence threats. This contributes to an integrated control of fighters by either ground-based or airborne controllers, which will increase the fighters' situational awareness and the ability to engage targets or to avoid threats, thereby increasing mission effectiveness.

TDL capabilities offer a near-term solution for exchanging information over a common network that is continuously and automatically updated.

TDL ensure the hardware and software support for communication capabilities in C4ISR applications during peacetime, as well as fight exercises and war. They are meant to serve NATO as well as the allied forces, which contribute to its continuous improvement according to threats and vulnerabilities dynamic. Currently, even Link16 and Link22 undergo a continuous adaptation process to new IT\&C technologies developed and implemented in NATO deployable networks. 
"Mircea cel Batran" Naval Academy Scientific Bulletin, Volume XIX - 2016 - Issue 2 The journal is indexed in: PROQUEST I DOAJ / Crossref / EBSCOhost / INDEX COPERNICUS I DRJI / OAJI I JOURNAL INDEX I I2OR / SCIENCE LIBRARY INDEX / Google Scholar / Academic Keys/ ROAD Open Access I Academic Resources / Scientific Indexing Services / SCIPIO I JIFACTOR

\section{BIBILOGRAPHY}

[1] Understanding Voice and Data Link Networking, Northrop Grumman, December 2014

[2] Link 22 Guidebook Overview, Northrop Grumman, July 2013

[3] Introduction to tactical digital information Link $\mathrm{J}$ and quick reference guide, Air Land Sea Application Center, June 2000

[4] https://en.wikipedia.org/wiki/Link 22

[5] https://en.wikipedia.org/wiki/MIL-STD-6011

[6] https://en.wikipedia.org/wiki/Link 16 